\title{
CARACTERIZAÇÃO DE FILMES DE SERICINA MODIFICADOS COM POLIETILENOGLICOL
}

\author{
D. B. DIAS ${ }^{1 *}$, A. P. $\operatorname{SONE}^{1 *}$, F. R. B. TURBIANI ${ }^{2}$, M. G. C. $\operatorname{SILVA}^{3}$, M. G. A. VIEIRA ${ }^{3}$ e \\ M. L. GIMENES ${ }^{1 *}$
}

\footnotetext{
${ }^{1}$ Universsidade Estadual de Maringá, Departamento de Engenharia Química

${ }^{2}$ Universidade Tecnológica Federal do Paraná - Câmpus Apucarana

${ }^{3}$ Universsidade Estadual de Campinas, Faculdade de Engenharia Química

*anapaulasone@hotmail.com.
}

\begin{abstract}
RESUMO - A sericina é uma proteína natural removida da seda pelo processo de degomagem. A recuperação desta pode agregar valor a este resíduo e minimizar o impacto causado por efluentes não tratados e resíduos sólidos. Biofilmes confeccionados por casting utilizando sericina e glicerol como plastificante foram quimicamente reticulados com diferentes concentrações de polietilenoglicol (PEG). Os filmes foram caracterizados através das análises de aspectos visuais, umidade, solubilidade em água e permeabilidade ao vapor d'água. Filmes de sericina produzidos pelo método de reticulação apresentam levemente amarelos, homogêneos, transparentes e visualmente atrativos onde o glicerol conferiu flexibilidade ao filme. As propriedades dos filmes de sericina dependem das composições utilizadas para formar o filme, que podem ser usadas para alcançar a flexibilidade desejada e minimizar a permeabilidade dos filmes.
\end{abstract}

\section{INTRODUÇÃO}

Os biofilmes são produzidos a partir de materiais biológicos, esses materiais possuem a capacidade de se biodegradar, ou seja, são convertidos em compostos simples quando presentes no meio ambiente (Chandra e Rustgli, 1998). Esse processo não ocorre com embalagens plásticas derivadas do petróleo.

Um polímero biodegradável que pode ser utilizado para confecção de biofilmes é a sericina. Sericina é uma proteína globular e solúvel em água que pode ser encontrada nos casulos do bicho-da-seda (Bombyx mori), sendo que os casulos são basicamente constituídos de $70-80 \%$ de fibroína e de $20-30 \%$ de sericina, onde é responsável por manter os fíos de fibroína ligados e dando coesão aos casulos (Zhang, 2002). A sericina é extraída pelo 
processo de degomagem, que pode ocorrer tanto por via física ou química ou, também, por enzimas. Nos estudos realizados por Tomadon Jr. (2011) na obtenção da sericina, foi determinado as melhores condições encontradas para a extração da sericina. Essas condições foram utilizadas por Turbiani (2011) na extração de sericina, para confecção de biofilmes de sericina reticulados com dimetiloluréia.

$\mathrm{Na}$ formulação dos biofilmes podem ser incorporados diversos tipos de aditivos, os mais utilizados são os plastificantes, que tem a função de melhorar a flexibilidade e o alongamento dos biofilmes, dessa forma, tornando-os menos quebradiços (Sothornvit e Krochta, 2005). Os agentes reticulantes, que por sua vez tem a função de promover ligações cruzadas entre as cadeias poliméricas, desta forma, podendo melhorar as qualidades mecânicas e a solubilidade dos filmes (Tsenoglou, 1988). O polietilenoglicol pode ser empregado como agente reticulante, de acordo com os parâmetros da Isso 9001:2000 é um composto que possui uma toxidez muito baixa e é estável em condições normal, além de o polietilenoglicol ser expelido do corpo sem ser metabolizado. Em relação ao meio ambiente, esse agente reticulante é solúvel em água, não se acumula no meio ambiente, sendo lentamente biodegradável.

Para produção de biofilmes, a técnica denominada "casting" é muito empregada, esta técnica consiste na preparação de uma solução filmogênica e a transferência de quantidades determinadas da mesma para um suporte para ocorrer à formação do filme pela evaporação do solvente (Cavalcanti et al., 2002).

O presente trabalho estudou as propriedades dos biofilmes de sericina reticulados com diferentes concentrações de polietilenoglicol (PEG), produzidos pela técnica “casting". Sendo analisados os aspectos visuais, a espessura, o conteúdo de umidade, a solubilidade em água e a permeabilidade ao vapor de água.

\section{MATERIAIS}

Para a confecção dos biofilmes, foi utilizada a proteína sericina proveniente dos casulos do bicho- da-seda, Bombyx mori, cedidos pela empresa Fiação de Seda BRATAC S. A. Além da utilização de glicerol como agente plastificante e polietilenoglicol (PEG) como agente reticulante.

\section{METODOLOGIA}

\subsection{Método de obtenção da solução de sericina}


A solução de sericina foi obtida em duas etapas. Na primeira etapa, os casulos adquiridos foram cortados em pequenos pedaços (aproximadamente $1 \mathrm{~cm}^{2}$ ) e posteriormente houve a adição de água destilada na proporção $3: 100(\mathrm{~m} / \mathrm{v})$, a extração foi realizada em autoclave com água quente a $120{ }^{\circ} \mathrm{C}$ e pressão manométrica de $1 \mathrm{kgf} / \mathrm{cm}^{2}$ durante 60 minutos.

A segunda etapa foi à precipitação da sericina na solução através do processo de congelamento, onde a solução de sericina extraída é congelada em freezer a $-20{ }^{\circ} \mathrm{C}$ durante 24 horas para ocorrer à precipitação. Posteriormente a solução foi retirada do freezer e deixada em temperatura ambiente até descongelar e filtrada a vácuo.

\section{2. Metodologia para preparação dos filmes}

Os filmes foram confeccionados através da técnica de "casting". Os filmes foram preparados a partir de uma solução filmogênica com fração mássica de sericina $(2 \% \mathrm{~m} / \mathrm{v})$ e contendo glicerol $(0,6 \mathrm{~g}$ de glicerol/g de sericina). Está solução foi homogeneizada por meio de agitação mecânica a $1000 \mathrm{rpm}$ por 1 hora em um agitador equipado com controlador de temperatura. Posteriormente, a solução foi aquecida á $70{ }^{\circ} \mathrm{C}$ e uma solução diluída de polietilenoglicol foi adicionada lentamente à solução filmogênica. Após manter essa solução sobre agitação durante 1 hora, alíquotas de $70 \mathrm{~mL}$ da solução filmogênica foram transferidas para placas de polipropileno com diâmetro de $15 \mathrm{~cm}$, e levadas a uma estufa de circulação de ar a $37^{\circ} \mathrm{C}$ por 16 horas para formação dos filmes por evaporação. Todo o fluxograma da metodologia é representado na Figura 1.

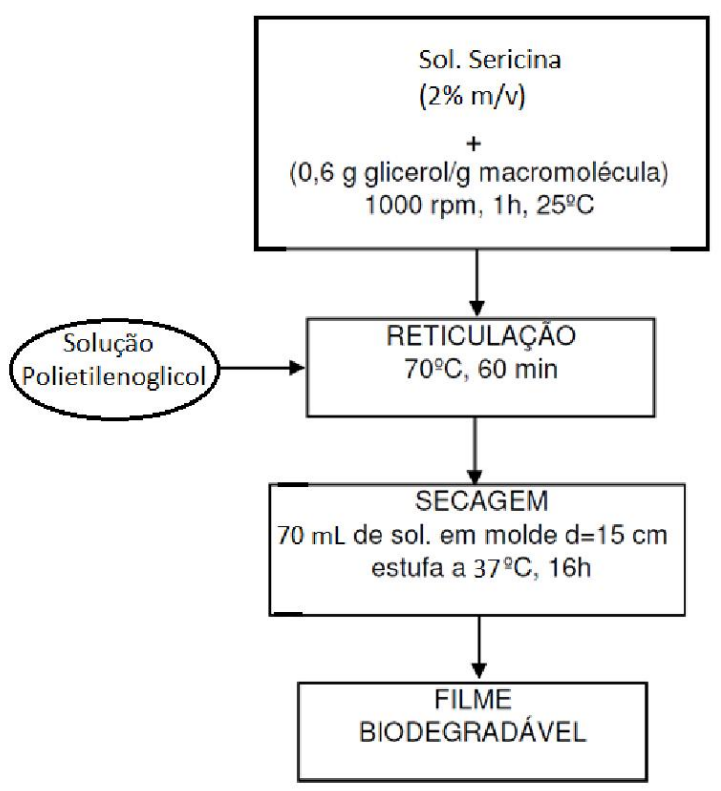

Figura 1 - Fluxograma da confecção dos biofilmes. 


\subsection{Caracterização dos biofilmes}

Os filmes foram caracterizados avaliando ao aspecto visual, espessura, teor de umidade, solubilidade em água e permeabilidade ao vapor de água. Todas as análises foram realizadas em triplicada para cada formulação de filme.

Antes da caracterização, os filmes foram mantidos em dessecadores para uniformização do conteúdo de umidade, em umidade relativa (UR) de $52 \%$, obtida por uma solução cloreto de sódio, durante três dias.

Aspecto visual: Seguindo os parâmetros estabelecidos por Gontard (1991), citados por Mali (2002), as características que foram verificadas são: continuidade, homogeneidade e manuseabilidade.

Espessura: A espessura foi determinada utilizando um micrômetro externo mecânico (Mitutoyo, modelo 103-137, graduação 0,01 mm). Foram realizadas cinco medidas aleatórias sobre uma área de $9,6 \mathrm{~cm}^{2}$ nos ensaios de permeabilidade para o calculo da espessura final através de uma média aritmética.

Conteúdo de umidade: A determinação da umidade ocorreu a partir da quantificação da massa inicial de amostras circulares dos filmes com diâmetro $2,5 \mathrm{~cm}$, sendo posteriormente submetidos à secagem a $105^{\circ} \mathrm{C}$ por $24 \mathrm{~h}$ em estufa e a massa seca quantificada novamente. $\mathrm{O}$ conteúdo de umidade $(\varpi)$ foi determinado pela Equação 1.

$$
\varpi=\frac{\left(m_{i}-m s_{f}\right)}{m_{i}} .100
$$

Onde $\varpi$ é a umidade do filme [\%], $m_{i}$ é a massa seca inicial a amostra [g] e $m s_{f}$ é a massa seca final da amostra $[\mathrm{g}]$.

Solubilidade em água: A quantidade de massa solúvel em água foi determinada a partir de amostras circulares de filmes de diâmetro de $2,5 \mathrm{~cm}$. A massa inicial dos filmes foram quantificadas $\left(m_{o}\right)$ e a amostra imersa em excesso de água destilada sobre agitação branda (125 rpm) em uma incubadora refrigerada com agitação sobre as seguintes condições, $25{ }^{\circ} \mathrm{C}$ durante 24 horas. Em seguida, a massa seca final $\left(m_{f}\right)$ das amostras foram quantificadas após as amostras serem submetidas à secagem a $105^{\circ} \mathrm{C}$ por 24 horas. Pela Equação 2 pode se calcular a quantidade de massa solubilizada.

$$
S_{w}=\frac{m_{i}(1-\varpi)-m_{f}}{m_{i}(1-\varpi)} .100
$$

Onde $S_{w}$ é a quantidade de massa solúvel [\%], $m_{i}$ é a massa seca inicial a amostra [g] e $m_{f}$ é a massa seca final da amostra [g]. 
Permeabilidade ao vapor de água: De acordo com o método E96-95 (ASTM, 1995b), a permeabilidade ao vapor de água foi determinada gravimetricamente. Foram utilizando pequenas células de teflon e alumínio, onde amostras circulares de filmes com diâmetro de 5 $\mathrm{cm}$ foram fixadas como é mostrado na Figura 2. As células permaneceram no interior de um dessecador com $75 \%$ UR, obtida por uma solução saturada de cloreto de sódio. O fundo da célula foi preenchido com cloreto de cálcio granular para manter a umidade relativa dentro da célula a $2 \%$. Durante sete dias, as células foram pesadas diariamente com uma balança analítica.

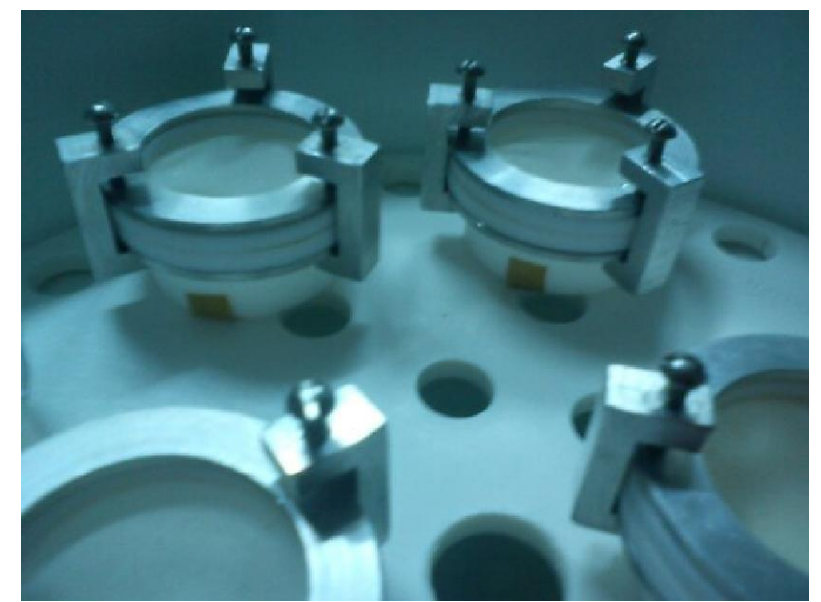

Figura 2 - Células de teflon e alumínio utilizadas na análise de permeabilidade ao vapor de água.

A permeabilidade ao vapor de água $\left(K_{\text {vap }}\right)$ foi determinado pela Equação 3, sabendo que a área da superfície livre exposta dos filmes para permear o vapor foi $6,9 \mathrm{~cm}^{2}$.

$$
K_{\text {vap }}=\frac{\stackrel{o}{G} \cdot \delta}{A_{e} \cdot \Delta P_{\mathrm{H}_{2} \mathrm{O}}}
$$

Onde $K_{\text {vap }}$ é a permeabilidade ao vapor de água $\left[(\mathrm{g} . \mathrm{mm}) /\left(\mathrm{m}^{2}\right.\right.$.dia.kPa $\left.)\right], \stackrel{o}{G}$ é a taxa constante de ganho de massa [g/dia], $\delta$ é a espessura inicial do filme [mm], $A_{e}$ é a área exposta do filme e $\Delta P_{H_{2} O}$ é a diferença de pressão parcial do vapor de água no ambiente próximo às duas faces do filme na temperatura do teste $[\mathrm{kPa}]$.

\section{RESULTADOS}

Os filmes de sericina com e sem o uso de agente reticulante na sua formulação, apresentaram boas qualidades de flexibilidade ao manuseio, fácil remoção das placas de suporte, levemente amarelados, homogêneos, transparentes e visualmente atrativos. 


\subsection{Aspecto visual}

As principais características verificadas foram homogeneidade, continuidade e manuseabilidade, sendo que os resultados encontrados são apresentados na Tabela 1. A grande maioria dos filmes apresentaram qualidades adequadas, apesar de suas qualidades exibirem uma menor homogeneidade com o aumento da concentração do agente reticulante.

Tabela 1 - Características relacionadas ao aspecto visual dos filmes confeccionados

\begin{tabular}{cccc}
\hline $\begin{array}{c}\text { Teor de Polietilenoglicol } \\
\text { (g PEG/g sericina) }\end{array}$ & Homogeneidade & Continuidade & Manuseabilidade \\
\hline 0,0 & $\mathrm{~A}$ & $\mathrm{~A}$ & $\mathrm{~A}$ \\
0,1 & $\mathrm{~A}$ & $\mathrm{~A}$ & $\mathrm{~A}$ \\
0,4 & $\mathrm{~A}$ & $\mathrm{~A}$ & $\mathrm{~A}$ \\
0,7 & $\mathrm{~B}$ & $\mathrm{~A}$ & $\mathrm{~A}$ \\
\hline
\end{tabular}

Nota: A - excelente, B - boa e C - deficiente.

\subsection{Umidade e solubilidade em água}

De acordo com a Tabela 2, pode se notar que o conteúdo de umidade para as diferentes formulações de filmes apresentaram uma evidente variação com a quantidade de agente reticulante empregada nos filmes. Os valores encontrados são maiores do que os valores encontrados por Bierhalz (2010) que estudou filmes de pectina e pectina BTM/alginato reticulado com cálcio e Norajit et al. (2010) que analisou filmes de alginato contendo extrato de ginseng.

Tabela 2 - Umidade e solubilidade em água dos filmes confeccionados

\begin{tabular}{ccc}
\hline $\begin{array}{c}\text { Teor de Polietilenoglicol } \\
\text { (g PEG/g sericina) }\end{array}$ & $\varpi\left[\mathrm{g} / 100 \mathrm{~g}_{\text {filme }}\right]$ & $S_{w}[\%]$ \\
\hline 0,0 & $17,85 \pm 0,42$ & $17,87 \pm 0,15$ \\
0,1 & $18,09 \pm 0,92$ & $15,91 \pm 1,39$ \\
0,4 & $27,65 \pm 1,35$ & $8,79 \pm 0,93$ \\
0,7 & $30,62 \pm 0,36$ & $3,43 \pm 0,27$ \\
\hline
\end{tabular}

Nota: Média \pm Desvio Padrão.

Os valores encontrados para a quantidade de massa solúvel dos filmes são menores dos encontrados por Turbiani (2011) que trabalhava com biofilmes de sericina reticulados com dimetiloluréia. Pode se notar a redução da massa solúvel dos filmes com o aumento da quantidade de agente reticulante utilizado, esse mesmo efeito foi encontrado por Turbiani (2011) também e por Zactiti e Kieckbusch (2006) que analisaram filmes de alginato de sódio reticulados com $\mathrm{CaCl}_{2}$. 


\subsection{Permeabilidade ao vapor de água e espessura}

Os filmes confeccionados possuem espessuras $(\delta)$ por volta de $0,12 \pm 0,01 \mathrm{~mm}$ e 0,19 $\pm 0,01 \mathrm{~mm}$, como apresentam na Tabela 3 .

Tabela 3 - Permeabilidade ao vapor água e espessura dos filmes confeccionados

\begin{tabular}{ccc}
\hline $\begin{array}{c}\text { Teor de Polietilenoglicol } \\
(\mathrm{g} \text { PEG/g sericina })\end{array}$ & $\delta[\mathrm{mm}]$ & $\begin{array}{c}K_{\text {vap }} \\
{\left[(\mathrm{g} . \mathrm{mm}) /\left(\mathrm{m}^{2} . \text { dia.kPa }\right)\right]}\end{array}$ \\
\hline 0,0 & $0,12 \pm 0,00$ & $2,63 \pm 0,07$ \\
0,1 & $0,12 \pm 0,01$ & $3,65 \pm 0,51$ \\
0,4 & $0,15 \pm 0,01$ & $7,11 \pm 0,49$ \\
0,7 & $0,19 \pm 0,01$ & $14,62 \pm 0,70$ \\
\hline
\end{tabular}

Nota: Média \pm Desvio Padrão.

Os valores encontrados para a permeabilidade ao vapor de água são valores próximos aos encontrados por Turbiani (2011) para os filmes de sericina reticulados com dimetiloluréia. Os valores da permeabilidade dos filmes sem agente reticulante e com uma proporção de 0,1 (g PEG/g sericina) também se aproximam aos valores encontrados por Bierhalz (2010) para filmes de pectina BTM e pectina BTM/alginado reticulados com cálcio.

Deve-se notar também que a permeabilidade ao vapor de água encontrada aumenta conforme o aumento da quantidade de agente reticulante empregado, sendo o contrário do que no trabalho de Turbiani (2011) que também envolve sericina. Acreditamos esse fato seja devido a presença de grupamentos $-\mathrm{OH}$ no polietilenoglicol, que não estão presentes no dimetiloluréia. Grupamentos como $-\mathrm{OH},-\mathrm{NH}$ e $-\mathrm{COOH}$, todos os três presentes na sericina, regulam a absorção de água na monocamada (Miyake et al., 2003). Considerando essa informação, pode ser concluído que o aumento dos grupos hidrofílicos provocados pela adição de polietilenoglicol, pode ter causado esse aumento na permeabilidade ao vapor de água com o aumento do agente reticulante.

\section{CONCLUSÃO}

Os filmes de sericina confeccionados apresentaram bons aspectos visuais, sendo homogêneos, levemente amarelos, transparentes, ter boa flexibilidade e ser fácil de manusear.

O resultado obtido para as análises de solubilidade e permeabilidade ao vapor de água apresentaram valores próximos aos encontrados na literatura. Porém o comportamento dos resultados da permeabilidade ao vapor de água em relação à adição de agente reticulante foi contrário ao encontrado na literatura. Para a confirmação das teorias levantadas, devem ser realizadas mais análises, como espectroscopia de absorção no infravermelho com transformada de Fourier (FTIR), microscopia eletrônica de varredura (MEV) e difração de 
raios-X, para obter um maior conhecimento da morfologia dos filmes e como ocorreu o processo de reticulação.

\section{REFERÊNCIAS}

ASSOCIAÇÃO BRASILEIRA DE NORMAS TÉCNICAS, NBR ISO 9001/2000: Sistemas de Gestão da Qualidade. Rio de Janeiro, 2001.

ASTM. Standard test methods of water vapor transmission of materials. American Society for Testing and Materials, Philadelphia, E 96-95, $1995 \mathrm{~b}$.

BIERHALZ, A. C. Confecção e caracterização de biofilmes ativos à base de pectina BTM e de pectina BTM/alginato reticulados com cálcio, Campinas: Universidade Estadual de Campinas, Tese de Mestrado, 2010.

CAVALCANTI, O. A., VAN DEN MOOTER, G., CARAMICO-SOARES, I., KINGET, R. Polysaccharides as excipientes for colon-specific coatings. permeability and swelling properties of casted films. Drug Dev. Ind. Pharm., New York, v.28, n. 2, p. 157-164, 2002.

CHANDRA, R.; RUSTGI, R. Biodegradable polymers. Progress in Polymers Science, v. 23, p. 1273-1335, 1998.

MIYAKE, H.; WAKISAKA, H.; YAMASHITA, Y.; NAGURA, M. Moisture characteristic and structure of high molecular weight sericin films. Polymer Journal, v. 35, n. 8, p. 683-687, 2003.

NORAJIT, K.; KIM, K. M.; RYU, G. H. Comparative studies on the characterization and antioxidant properties of biodegradable alginate films containing ginseng extract. Journal of Food Engineering, v. 98, p. 377-384, 2010.

SOTHORNVIT, R., KROCHTA, J. M. Plasticizers in edible films and coatings. Ed. HAN, J. H. In:Innovations in Food Packaging. Elsevier, 2005.

TOMADON JR., J. Obtenção da proteína sericina, com alta massa molecular, a partir de casulos Bomxy mori. Maringá: Universidade Estadual de Maringá, Tese de Mestrado, 2011.

TSENOGLOU, C. Rubber elasticity modulus of interpenetrating heteropolymer networks. In: DICKIE, R. A.; LABANA, S.S.; BAUER, R.S. Cross-linked polymers: Chemistry, Properties and Applications. Washington: American Chemical Society, p. 6061,1988 .

TURBIANI, F. R. B. Desenvolvimento e caracterização de filmes biodegradáveis de sericina e PVA reticulados com dimeltiloluréia. Maringá: Universidade Estadual de Maringá, Tese de Doutorado, 2011.

ZHANG, Y. Q. Application of natural silk protein sericin in biomaterials. Biotechnology Advances, v. 20, p. 91-100, 2002. 